\title{
Application of Law of Equal Expectations to Oil Production in California*
}

\author{
By Carl H. Beal $\dagger$ and E. D. Nolan, $\ddagger$ Washington, D. C.
}

(Chicago Meeting, September, 1919)

IN February, 1918, the conclusion was published by Lewis and Beal "that wells of equal output on the average will produce equal amounts of oil in the future, regardless of the ages of the wells." This conclusion was based upon the study of data collected principally in Oklahoma and was not known at that time to be true for other oil fields. An abundance of statistical proof was later collected by the senior author of the present paper, which showed that the conclusion was undoubtedly well founded and that it applied to other fields as well. Accordingly, it was later restated $^{2}$ as the "law of equal expectations" as follows: "If two wells under similar conditions produce equal amounts during any given year, the amounts they will produce thereafter, on the average, will be approximately equal, regardless of their relative ages."

Although only scanty data from the California oil fields were available at the time this publication was prepared, sufficient information was analyzed upon which to base the insert on Fig. 80, which showed beyond a doubt that the law held at least for a part of the Midway oil field in California. Recently the authors have collected more complete data in California, and it is the purpose of this paper to explain the method used in demonstrating the truth of the law and, in addition, to give several methods by which curves constructed in accordance with this law can be used in a practical way with ease and accuracy.

\section{The Family Curve}

The law of equal expectations means that each individual of a group of wells producing under similar conditions will decline along approximately the same type of curve, the rapidity of decline varying with the output

* Published by permission of the Director, U. S. Bureau of Mines.

† Petroleum Technologist, U. S. Bureau of Mines.

$\ddagger$ Consulting Petroleum Engineer, U. S. Bureau of Mines.

${ }^{1}$ Some New Methods of Estimating the Future Production of Oil Wells. Trans. (1918) 69, 492.

${ }^{2}$ Carl H. Beal: The Decline and Ultimate Production of Oil Wells with Notes on the Valuation of Oil Properties. U. S. Bureau of Mines Bull. 177 (1919) 36. 
of the well. For instance, if the first year's production of a well is very large, its decline will be much more rapid than that of a well having a smaller output. Furthermore, the second well will produce oil at the same rate as the first well after the latter has declined to the same output as the second. Inasmuch as the wells in a group, under similar conditions, produce oil along a certain curve, if this curve can be made up from decline records of wells of different size, we are able to forecast with accuracy the decline of normal wells of different size in that area. Such curves have been built up for different fields in California. They have been called "family" curves for lack of a better name and because the decline of wells of different output will follow the same curve.

The use of the family curve is not claimed to be original in the present paper, as its possibilities were given by Lewis and Beal, ${ }^{3}$ and one method of preparing such a curve and its advantages were later briefly given by Beal. ${ }^{4}$ The particular method of building up the family curve, however, is unique, and the various methods of using the curve for estimating the life and future production of wells are new.

\section{Construction of Family Curve}

In preparing family curves for other oil fields, it has usually been necessary to use the production records of tracts, for in most fields the output of all wells on a tract is gaged in the same tank. The use of such records has some advantages and some disadvantages. If the records of individual wells are used, there will be smaller chance of the entrance of such complex factors as the undue maintenance of production by the bringing in of new wells on a tract. In the oil ficlds of California the production records of individual wells are usually available, and the following curves are based entirely on such records.

Fig. 1 shows a family curve based on the production records of wells in a California oil field. Briefly, the preparation of such a curve consists of, first, choosing the records of all normal wells - such as those unaffected by redrilling, cleaning out, deepening, water encroachment, etc.; second, plotting the yearly decline of the largest well $A$ and joining the points showing the production per year by straight lines; and, finally, taking successively smaller wells and plotting the decline of each well, the initial or first year's point being located on the production curve of the largest well at the proper point, and subsequent points at spaces to the right representing years. For instance, in Fig. 1, the points marked $A$ represent the decline of the largest well, those marked $B$ represent the

${ }^{3}$ Trans. (1918) 59, 512, Fig. 9.

- U. S. Bureau of Mines Bull. 177 (1919) 198. 
decline of the second largest well, and points $C, D, E, F, G$, and $H$ the declines of the smaller wells. The initial point, or the first year's production, of well $B$ is located on the curve of well $A$ at a distance of $90,000 \mathrm{bbl}$. (the first year's production) above the horizontal axis. This procedure is repeated for the smaller wells.

After the declines of two or three wells have been plotted the average line can be drawn by determining the numerical average of points within adjoining vertical segments of the cross-section paper and drawing the curve through the average points. From this time on, the decline of the smaller walls may be begun on the average curve. For instance, in Fig. 1, after the records of wells $A$ and $B$ were plotted, the heavy average line was drawn to point $X$ and the first year's production of wells $C, D$, and $E$

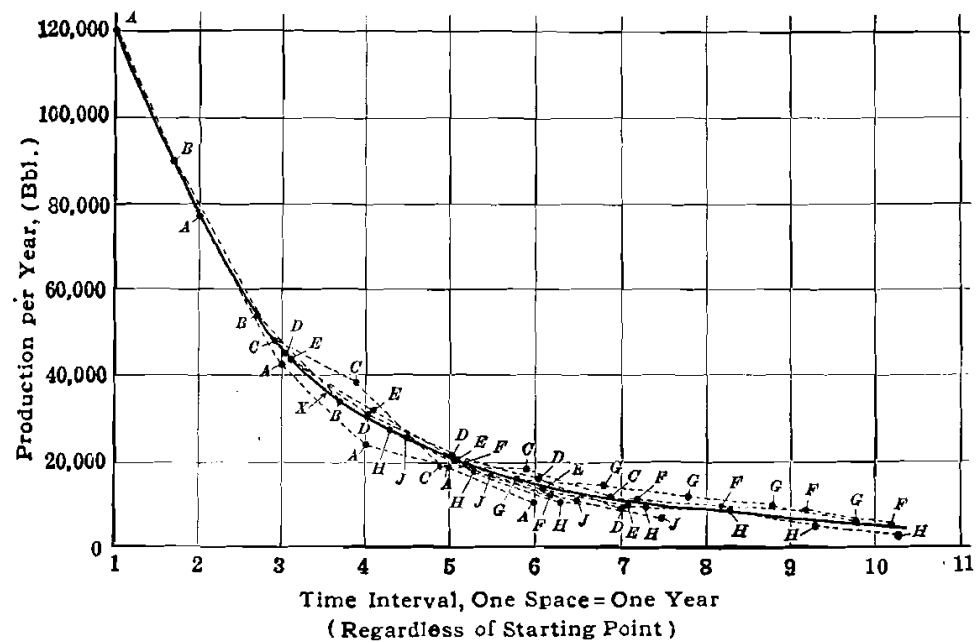

Fig. 1.-Showing Method USED In constructing a FAMTLY CURVe From production RECORDS OF INDIVIDUAL FIELDS.

were plotted on the curve. The process of gradually extending the family curve and plotting on it the initial year's production of smaller wells is continued until all the data are plotted. Rarely will a case be found where the plotting of more than three or four wells is necessary to determine the beginning of the average curve. The greatest difficulty is usually experienced in determining the proper rate of curvature of the decline curve when it begins to flatten out. This part of the curve usually represents the exhaustion of the high gas pressure, which is closely associated with the rate of expulsion of oil from the well. After part of the gas pressure is released, the curve representing the decline of practically any well, unless changed by some mechanical accident, trends only slightly downward at a rate decidedly less than its previous rate of decline.

vol. $\mathrm{LXV},-22$. 
It should be noted that the entire length of the average, or family curve, as shown by the heavy line in Fig. 1, is the result of the plotting of past production. Sufficient data are usually available so that the curve can be oarried even to the point representing minimum economic production, so that the necessity of projecting the curve to represent production in the future is obviated. The family curve in this case is based absolutely on actual performance. The objection to some curves is the necessity of projecting them, the projection in many cases varying with the person who makes it. This is not true, however, with the family curve, especially when the records of several wells representing different outputs are available.

In a new field, such as the Montebello field, it might be found advantageous to construct a curve with a monthly time interval as the horizontal scale. Then with wells but a few months old, a family curve may be prepared with but little difficulty.

Another method ${ }^{5}$ of preparing a family curve is to divide the production records into classes representing different productivity. The yearly output of all wells in the highest class (those that made 110,000 to 120,000 bbl. the first year) is averaged; then the yearly output of the next highest class (those that made 100,000 to $110,000 \mathrm{bbl}$. the first year) is averaged, and the average points plotted and so on until all the averages are obtained.

\section{Use of Family Curve}

Because wells of different size decline along the same type curve, the work of making estimates of future production is greatly simplified. The life of the average well can also be quickly determined and the limits of decline may be shown graphically. Furthermore, the future yearly production of a well of any output may be read directly from the average family curve.

\section{Future Production Curves}

In Fig. 2, curve $A$, above the family curve $B$, was determined by adding the future production of wells of different output as shown by the family curve and then plotting these future production estimates vertically above the point on the family curve representing the first year's production of a well. For instance, assume a point on the family curve, representing 21,000 bbl. to be the first year's production of a well of that output. The second year's production will be one year to the right, the third year's production two years to the right, etc., to the point of minimum economic production. These estimated annual productions, with the exception of the first year, as shown on the family

'Carl H. Beal: U. S. Bureau of Mines Bull. 177 (1919) 198, and Fig. 80. 
curve, are added together and plotted vertically above the point on the family curve representing the first year's production, and a curve $A$ drawn through the points. In the present instance, the yearly production, as represented by the family curve, is as follows:

$\begin{array}{cccr}\text { Year } & \begin{array}{c}\text { Production, } \\ \text { Barrels }\end{array} & \text { Year } & \begin{array}{c}\text { Production, } \\ \text { Barrels }\end{array} \\ 1 & 21,000 & 6 & 5,500 \\ 2 & 15,000 & 7 & 4,000 \\ 3 & 11,500 & 8 & 2,000 \\ 4 & 9,000 & 9 & 1,000 \\ 5 & 7,000 & \text { Total } \ldots \ldots \ldots . & \mathbf{7 6 , 0 0 0}\end{array}$

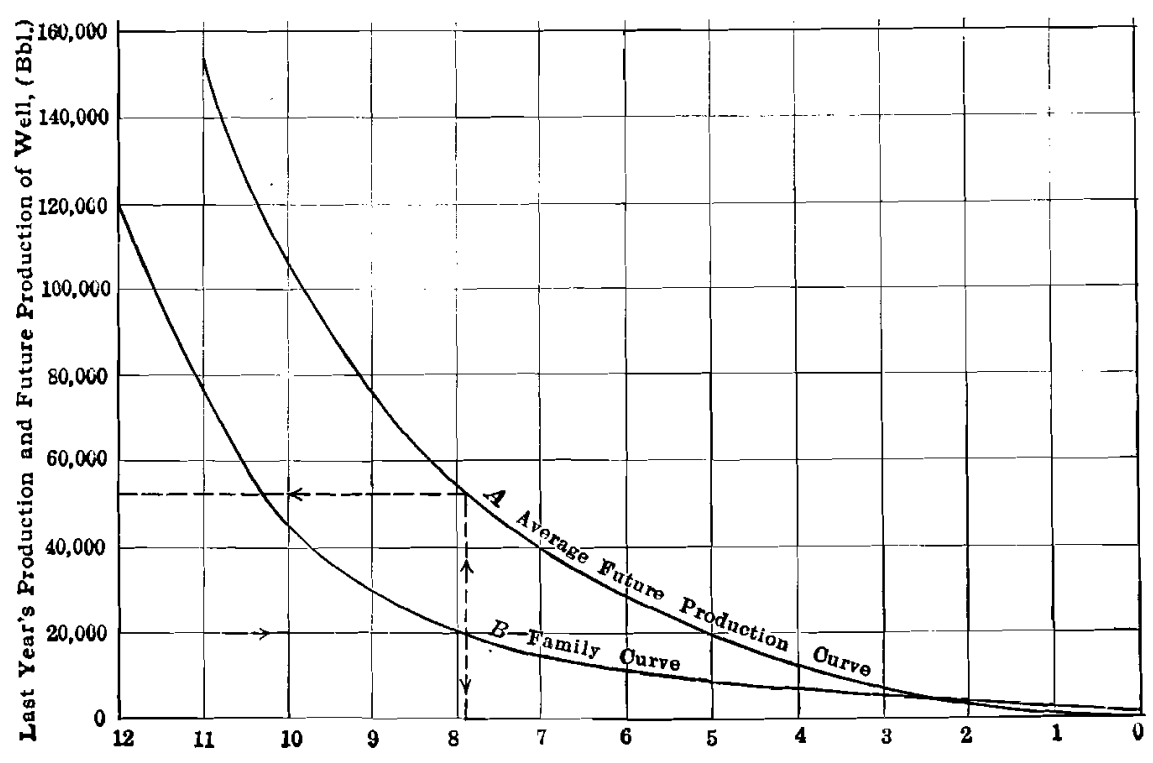

Remaining Life of Well, (Years)

Fig. 2.-Average future production and "family" curves of a Catifornia OIL FIELD.

The average ultimate production of the well will be $76,000 \mathrm{bbl}$., and the future $55,000 \mathrm{bbl}$. $(76,000-21,000)$. The future production, 55,000 bbl.; is plotted vertically above the point on the family curve representing 21,000 bbl. Because of the law of equal expectations, the production of $21,000 \mathrm{bbl}$. could represent the most recent years' production if desired; that is, suppose the well during 1918, its third year, produced $21,000 \mathrm{bbl}$. Then if the well is an average well, it will produce $55,000 \mathrm{bbl}$. from 1919 to 1926 , inclusive, and it produced 30,000 and 45,000 bbl. during 1917 and 1916, respectively.

By the use of curve $A$, the future production of a well at any period of its life may be determined by selecting the production for the last 
year. Find this amount on the left margin and trace the line to the right to a point where it intersects the family curve, follow the vertical line through this point upward to its intersection with the future production curve, thence to the left margin of the figure. The reading is the future production of the well selected. For example, take a well that made $20,000 \mathrm{bbl}$. during the first year, follow the horizontal line to the right to its intersection with the family curve, thence upward to its intersection with the future production curve and thence to the left margin where 53,000 bbl. is indicated as the average future production of a well of that output. The estimate would have been correct if the production of $20,000 \mathrm{bbl}$. represented the most recent year's production instead of the first year's production.

\section{Determining Ayerage Life of Wells of Different Size}

In the lower margin of Fig. 2 will be found figures that decrease to the right. These figures represent the remaining average life of wells and are determined by counting the years of remaining life for wells of different output, as shown by the family curve. For instance, the remaining life of the well that made $20,000 \mathrm{bbl}$. during the first year, by reading downward on the vertical line passing through the point on the family curve representing $20,000 \mathrm{bbl}$,, is found to be 8 years. From this curve, it is evident that the lives of oil wells vary directly as the volume of production, for the larger the production, the longer the remaining life.

\section{Ultimate Production Curves}

If desired, the future production may be added to the last year's production, which will give the ultimate production direct. These statistics may be plotted for wells of different size and curves thus constructed. Both this and the average future production curves may be plotted if desired, although the ultimate production may readily be obtained by first determining the future production and adding to it the past year's production.

\section{Another Method of Showing Future Production Curve}

The curve representing future production may be expressed as an average appraisal curve if desired. The appraisal curve was named by Lewis and Beal, ${ }^{6}$ and consists of showing the relation between the first year's production of a well and its ultimate production. The suggestion was made that additional curves showing the actual future could be plotted by subtracting from the ultimate production the past year's

G Trans. (1918) 59, 492. 
production. The future production curve, as arrived at by the family curve, may be expressed in the same way; that is, the past year's production may be used as the abscissa and the future production may be shown as the ordinate. In this way, the curve begins a distance to the right of the lower left-hand corner, which represents the minimum economic production to which the average well in a district can be pumped, and rises gradually to the right, having the same form as appraisal curves. There is no particular advantage in this form of curve over curve $A$, Fig. 2, which likewise represents future production directly.

\section{Erratic Wells}

In any field, certain wells will be found having a decline wholly different from that of the family curve of that group; these usually are con-

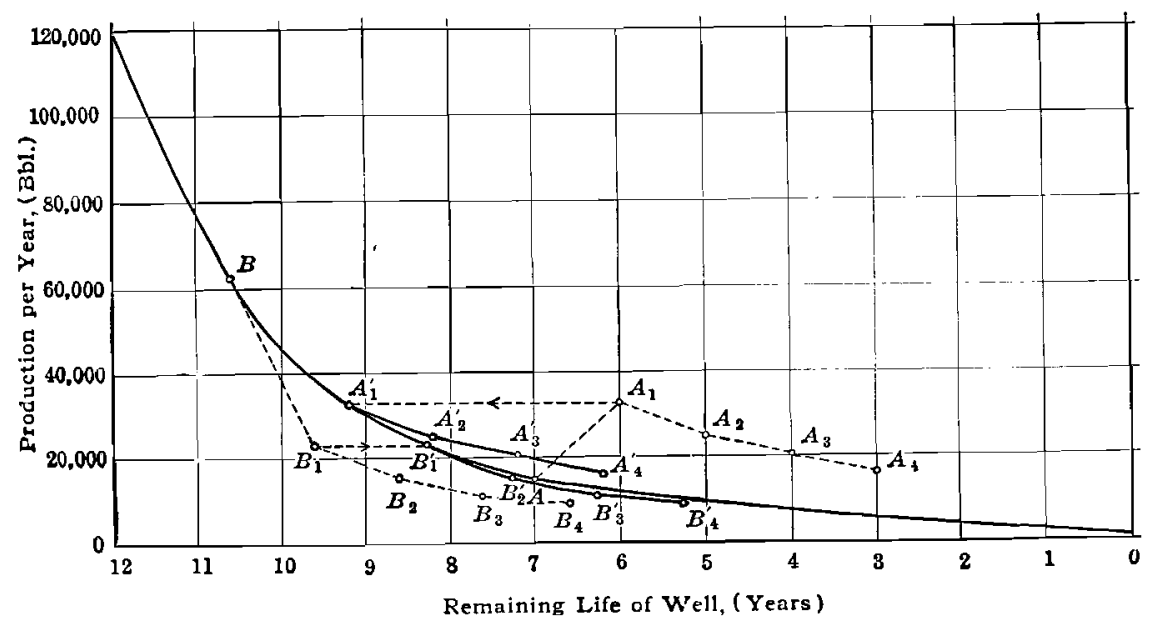

Fig. 3.-Proddction of erRatic WELls plotted on "FAMILY" CURVE to BHow THAT SUCH WELLS USUALLY DECLINE ALONG GOME PART OF THE CURVE'AFTER ERRATIC

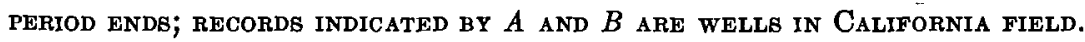

sidered abnormal wells. The causes of these wells may be divided roughly into three classes-geological, accidental, and lack of histories of wells. Geological causes may be either a very thick series of oil sands with varying gas pressures or the comparatively sudden invasion of edge water. In certain small districts, such as the area in Sec. 27, T. 19 S., R. 15 E. in the Coalinga field, or that near Fellows in the North Midway field, the thickness of oil-bearing series is from 500 to $700 \mathrm{ft}$. (152.4 to $213.3 \mathrm{~m}$.). Wells drilled through this thick series of alternating oil sands and shales often show an increasing production for 2 or 3 years after inception. After having reached their maximum, however, their decline follows the family curve. The probable explanation of this increase is as follows: Such wells penetrate a number of rich oil sands, but under 
varying gas pressures. When first brought in only those sands with the higher gas pressures are able to produce but time permits a lessening and readjusting of the pressures and all sands are able to contribute to the well's production. Curve $A$, Fig. 3 , shows the production of a well of this type and its relation to the family curve. Wells producing from a sand suddenly invaded by water may show an increase in production just prior to the appearance of the water, but almost invariably show a rapid decline and a sudden end.

Accidental causes of erratic wells might also be called mechanical causes. The "oil string" may collapse, shutting off its production, or a redrilling job may be a failure, causing the abrupt ending of the well's life. In the loose unconsolidated sands of the California fields, shale may cave in, shutting off the perforations. These accidents usually cause a sharp break in the decline of the well and a consequent dropping away from the family curve. After this initial break, its decline through the remainder of its life usually follows some other part of the family curve. The decline indicated by $B$, Fig. 3 , is of such a well.

Another class of erratic wells that often cause trouble are those that have been deepened. When a well is deepened into lower sands or is redrilled, with a consequent opening of new sands, or possibly shutting off other oil sands, it must be treated as a new well, and accordingly a new part of the family curve selected as its decline curve.

Wells varying from the family curve sufficiently to be termed erratic wells are rare, certainly less than 10 per cent. of the total wells in the California fields. The divergence in most erratic wells takes place during the first 2 or 3 years of the life of the well. From that time on, the output of the well follows some part of the family curve.

\section{Estimating Future Production of Wells Above and Below the Average}

Most wells in a field will follow the family curve with fair exactness. Some will trend slightly above it, follow it for a year or so, and finally fall below. One is usually safe, however, in making estimates of the future production, if he assumes the well to be an average well; he is unwise, however, if he makes no effort to determine the amount a well is above or below the average, for if it deviates far from the average the estimate may and should be modified accordingly. Fortunately, as most estimates of future production are made by using the last year's production, the curve tends to correct itself by automatically shifting the point on the family curve at which the estimate is made to the right or left, according to whether the curve is below or above the average. This may be more clearly shown by taking an example. Suppose well $A$, Fig. 3 , has produced 2 years, as shown by $A$ and $A_{1}$; the estimate of 
future production is made by applying the last year's production (indicated by $A_{1}$ ) to the family curve, thus shifting the point $A_{1}$ to the left to where a horizontal line through it intersects the family curve. As subsequent production from this particular well has proved (see points $A^{\prime}{ }_{2}, A^{\prime}{ }_{3}$ and $A^{\prime}{ }_{4}$ ), the estimate of future production would have been slightly above the average curve.

Another example will serve to show the method by which the estimates of future production of wells below the average will tend to correct themselves. Suppose well $B$, Fig. 3 , has produced 2 years $\left(B\right.$ and $B_{1}$ ), an estimate of its future production will be made from point $B^{\prime}{ }_{1}$ on the family curve. Subsequent production would indicate that the well produced along a curve $\left(B^{\prime}{ }_{2}, B^{\prime}{ }_{3}\right.$ and $\left.B^{\prime}{ }_{4}\right)$ almost coincident with the family curve. If estimates are made yearly, they become closer and closer even though the well may produce along a curve considerably above or below the average.

\section{Family Curve Applied to Tract or Properties Production}

Where the individual well records are lacking or where the average well production is quite small, it may be either necessary or convenient to construct a family curve for a group of tracts rather than for a group of individual wells. Such curves when constructed from a number of properties and applied to properties that are sufficiently drilled are quite accurate.

\section{Value of Family Curve}

The greatest advantage of the family curve is the fact that it is based entirely on history; it usually has no projections and it is not difficult to prepare. Furthermore, its advantage over the appraisal curve is that it can be prepared with less data. In fact, the statistics represcnting the decline of a dozen wells might suffice for the preparation of a curve, the decline of which represents the decline of wells of different size in an area where conditions affecting production are practically equivalent. The accuracy of the curve, however, is increased in direct proportion to the number of records used in its preparation.

Another advantage over appraisal curves is that the future production of a well from its first year can be estimatcd more readily when the decline of the well is above or below the average. Owing to the fact that the last year's production is used and that erratic wells after their abrupt change follow a portion of the family curve, the curve reduces error to a small amount, and tends to correct errors due to its own limitations. The simplicity and completeness of the curve are the principal arguments in its favor. One may read direct the future production of a well, its probable life in years and its probable production in any year in the future. 